\title{
Cloning, sequencing, characterisation and implications for vaccine design of the novel dihydrolipoyl acetyltransferase of Neisseria meningitidis
}

\author{
D. A. A. AlA' ALdEen, A. H. WeStPhal*, A. DE KOK*, VIVIENNE Weston, M. S. ATtA, \\ T. J. BALDWIN, JULIA BARTLEY† and S. P. BORRIELLO $\ddagger$
}

Department of Microbiology and the Institute of Infections and Immunity, University Hospital, Queen's Medical Centre, Nottingham NG7 2UH, *Department of Biochemistry, Agricultural University, Wageningen, Dreijenlaan 3, 6703 HA Wageningen, The Netherlands and $\ddagger$ Department of Biological Sciences, University of Durham Science Laboratories, South Road, Durham DH1 $3 L E$

\begin{abstract}
A $\lambda$ Zap-II expression library of Neisseria meningitidis was screened with a rabbit polyclonal antiserum (R-70) raised against $c$. 70-kDa proteins purified from outer membrane vesicles by elution from preparative SDS-polyacrylamide gels. Selected clones were isolated, further purified, and their recombinant pBluescript SKII plasmids were excised. The cloned DNA insert was sequenced from positive clones and analysed. Four open reading frames (ORFs) were identified, three of which showed a high degree of homology with the pyruvate dehydrogenase (E1p), dihydrolipoyl acetyltransferase (E2p) and dihydrolipoyl dehydrogenase (E3) components of the pyruvate dehydrogenase complex (PDHC) of a number of prokaryotic and eukaryotic species. Sequence analysis indicated that the meningococcal E2p (Men-E2p) contains two N-terminal lipoyl domains, an E1/E3 binding domain and a catalytic domain. The domains are separated by hinge regions rich in alanine, proline and charged residues. Another lipoyl domain with high sequence similarity to the Men-E2p lipoyl domain was found at the $\mathrm{N}$ terminal of the E3 component. A further ORF, coding for a 16.5-kDa protein, was found between the ORFs encoding the $\mathrm{E} 2 \mathrm{p}$ and $\mathrm{E} 3$ components. The identity and functional characteristics of the expressed and purified heterologous Men-E2p were confirmed as dihydrolipoyl acetyltransferase by immunological and biochemical assays. $\mathrm{N}$-terminal amino-acid analysis confirmed the sequence of the DNA-derived mature protein. Purified Men-E2p reacted with monospecific antisera raised against the whole E2p molecule and against the lipoyl domain of the Azotobacter vinelandii E2p. Conversely, rabbit antiserum raised against Men-E2p reacted with protein extracts of $A$. vinelandii, Escherichia coli and $N$. gonorrhoeae and with the lipoyl and catalytic domains of E2p obtained by limited proteolysis. In contrast, the original R-70 antiserum reacted almost exclusively with the lipoyl domain, indicating the strong immunogenicity of this domain. Antibodies to Men-E2p were detected in patients and animals (rabbits and mice) infected with homologous or heterologous meningococci or other neisserial species. These results have important implications for the understanding of PDHC and the design of future outer membrane vesicle-based vaccines.
\end{abstract}

\section{Introduction}

Meningococci produce a relatively complex outer membrane that contains a large number of proteins

Received 27 March 1996; accepted 6 June 1996.

Corresponding author: Dr D. A. A. Ala'Aldeen.

†Present address: Central Public Health Laboratory, 61 Colindale Avenue, London NW9 5HT. (outer-membrane proteins, OMPs). Many of these proteins are expressed constitutively, but others are environmentally regulated. Recently, there has been a major focus on OMPs for vaccine production, particularly against group B meningococci, and a number of relatively crude OMP mixtures were tested in clinical trials with various degrees of reported efficacy [1]. Following large scale placebo-controlled, randomised double-blind trials, only the vaccines produced in 
Norway and Cuba showed significant protective efficacy. The Norwegian vaccine consisted of OMPs from the Norwegian epidemic strain of Neisseria meningitidis, B:15:P1.7.16 and was given to children aged 14-16 years. It produced a point estimate of protective efficacy of $57 \%$ after a 30 -month follow-up and was, therefore, considered insufficiently effective for general use [2]. The Cuban vaccine consisted of group C capsular polysaccharide mixed with OMPs from a Cuban epidemic strain, B:4:P1.15. When given to children aged 10-16 years, it offered an estimated point efficacy of $83 \%$ after 16 months of follow-up [3] and, as a result, the vaccine is now incorporated into the routine childhood vaccination programme in Cuba. Although the Cuban trial did not directly address efficacy in children $<10$ years old, follow-up studies of the mass vaccination have suggested that the overall protective efficacy based on vaccine coverage and incidence of disease in children under 6 years old is $c$. 93\% [3]. However, when the Cuban vaccine was tested in a case-control study in Brazil, protective efficacy was reported to vary with age. The vaccine was effective in children aged 4 years and older, but not in younger children [4].

Although these OMP vaccine preparations are enriched for major class antigens such as serotype (class 2/3) and serosubtype (class 1) OMPs, they also contain significant amounts of other uncharacterised proteins. This makes the search for component(s) relevant to protection in man, and standardisation of preparations for future use, extremely complicated. Moreover, most of the OMP vaccines used consist of outer membrane vesicle (OMV) preparations [2-4]. Such OMVs are likely to include transmembrane, inner membrane or even cytoplasmic components. It is not known which of these components contribute most to antibody-mediated or cell-mediated immune responses and long-term protection from disease. It is possible that these OMVs contain a mixture of antigens, with varying regulating effects on the immune system. Furthermore, there are numerous cell components which are structurally, functionally or immunologically conserved across prokaryotic and eukaryotic cells and which may have been included, unwittingly, in the OMV vaccine preparations. Inclusion of such components in vaccines will carry the risk of breaking immune tolerance with concomitant risk of inducing autoimmune disease. Therefore, more information is desirable on the individual meningococcal OMV antigens in terms of structure and function to facilitate development of an ideal meningococcal vaccine.

OMVs consisting of a wide range of outer-membrane and other proteins were prepared in an earlier study. Purified proteins of $c$. $70-\mathrm{kDa}$ were prepared from these OMVs by elution from preparative SDSpolyacrylamide gels and the antigens were used to raise rabbit polyclonal antiserum (R-70) [5]. Immuno- blot experiments showed that this antiserum contained antibodies against several co-migrating meningococcal proteins, including the iron-regulated FrpB and non iron-regulated proteins $[5,6]$. The exact identity of these different co-migrating proteins has been unclear.

We, and others, have previously characterised FrpB and demonstrated that it is a partially surface-exposed OMP [5-7]. More recently, Pettersson et al. [8] cloned and sequenced FrpB and showed that it is related to the family of TonB-dependent proteins. However, its functional attributes remain largely unclear. With regard to the non-iron-regulated $70-\mathrm{kDa}$ protein(s), very little is known. Aoun et al. [9] showed that murine sera raised against live meningococci were bactericidal to gonococci and reacted preferentially (in immunoblots) with a highly conserved and constitutively expressed $70-\mathrm{kDa}$ protein. It is not clear whether this immunoreactive $70-\mathrm{kDa}$ protein and the one(s) previously purified in our laboratories $[6,10]$ are the same.

Therefore, in this study the R-70 antiserum was used to screen a DNA expression library in an attempt to clone and further identify those OMV components that were recognised by this polyclonal rabbit antiserum. The identification, sequence analysis and functional determination of one of these reactive components, the dihydrolipoyl acetyltransferase component of the pyruvate dehydrogenase complex (PDHC) is reported here. The detection of a gene cluster which consists of all the necessary components of the PDHC as well as a unique reading frame which has not been detected in pathogenic organisms is also reported.

\section{Materials and methods}

\section{Bacterial strains, vectors and total protein extraction}

N. meningitidis strains SD (B:15:P1.16), AS (A:4:P1.7) and $\mathrm{EB}(29 \mathrm{E})$ were grown in Mueller Hinton broth (MHB) overnight at $37^{\circ} \mathrm{C}$ in air with $\mathrm{CO}_{2} 5 \%$. Ironrestriction, where required, was achieved by the addition of $25 \mu \mathrm{M}$ desferrioxamine (Ciba-Giegy, Horsham). Escherichia coli strain XL1 Blue was obtained from Stratagene (Cambridge). E. coli strain TG2, a recA ${ }^{-}$version of $\mathrm{TG} 1$, i.e., thi $i^{-}$, sup E44, $\left[\operatorname{Res}^{-} \operatorname{Mod}^{-}(\mathrm{k})\right], \quad \mathrm{F} \quad\left(\right.$ traD36 pro $\left.\mathrm{A}^{+} \mathrm{B}^{+}\right)$, laq $\mathrm{I}^{9} \mathrm{Z} \alpha \Delta \mathrm{M} 15 \Delta$ (lac-pro), was used for cloning and expression of plasmid-encoded proteins [11]. Total protein extracts from $N$. meningitidis strain $\mathrm{SD}$ and $E$. coli XL1-Blue carrying plasmid, before or after isopropyl $\beta$-D thiogalactopyranoside (IPTG)-induction, were prepared as described previously [12].

\section{Sera, SDS-PAGE and immunoblots}

The rabbit antiserum against purified $c$. 70-kDa OMV proteins of meningococci (R-70) was raised and 
characterised previously [10]. Before use, the R-70 antiserum was adsorbed once with immobilised $E$. coli lysate (Pierce, Pierce and Warriner, Chester) as described by the manufacturers. Rabbit antisera to whole cells (live organisms) of meningococcal strains $\mathrm{SD}, \mathrm{AS}, \mathrm{EB}$ and the commensal $N$. lactamica strain were raised in New Zealand White rabbits as described previously [5]. Rabbit antiserum to meningococcal E2p (Men-E2p, see below) was raised by inoculating a New Zealand White rabbit, by subcutaneous injection, with five doses of $100 \mu \mathrm{g}$ of purified protein (eluted from SDS-polyacrylamide gels) suspended in $500 \mu \mathrm{l}$ of phosphate-buffered saline (pH 7.2; PBS, Oxoid) and mixed with equal volumes of Freund's complete (first injection) and incomplete (the subsequent fortnightly booster injections) adjuvants. Pre-immune normal rabbit serum was also obtained. Murine polyclonal antisera to live cells of meningococcal strains SD and B16B6 (B:2a:P1.2) and murine monoclonal anti-FrpB (Mab-M70) were raised and characterised previously $[6,13]$. Pre-immune normal mouse serum was also obtained. Human convalescent sera were taken from patients 4 weeks after recovery from meningococcal disease (meningitis or septicaemia, or both) caused by different meningococcal strains, including strain SD, JB (B:NT) and GLD (C:2a:P1.10). A human convalescent serum was also obtained from a patient who had recovered from gonococcal pelvic inflammatory disease. Normal human serum was obtained from an individual with no prior history of infection with $N$. meningitidis or $N$. gonorrhoeae.

SDS-PAGE and immunoblots of the rabbit, murine and human antisera against total protein extracts and purified Men-E2p (below) were performed as described previously [14].

\section{Gene library screening, cloning and sequencing}

The R-70 antiserum was used to screen a previously constructed gene library of $N$. meningitidis (strain SD) DNA in $\lambda Z$ Zap II [12]. Approximately 50000 plaques, seeded on $E$. coli strain XL1 Blue, were lifted in duplicates on to nitrocellulose membranes (Schleicher and Schuell, supplied by Anderman, Kingston-uponThames) pre-impregnated with $0.5 \mathrm{mM}$ IPTG. As the rabbit R-70 antiserum was raised against denatured meningococcal OMV proteins, one copy of the plaquelife membrane was denatured by heating at $56^{\circ} \mathrm{C}$ for $30 \mathrm{~min}$ in protein-denaturation buffer (containing SDS $1 \%$ and 2-mercaptoethanol $0.2 \%$ ) and the other copy was left untreated. Both membranes were blocked in blocking buffer (bovine serum albumin 3\%, Tween 20 $0.1 \%$ in PBS) for $1 \mathrm{~h}$, and then incubated with the R-70 antiserum (diluted 1 in 1000) for $3 \mathrm{~h}$ at room temperature followed by peroxidase conjugated goat anti-rabbit serum as previously described $[5,10]$. Positive plaques were isolated and purified and recombinant pBluescript SKII plasmids were excised with the ExAssist helper phage (Stratagene). Two

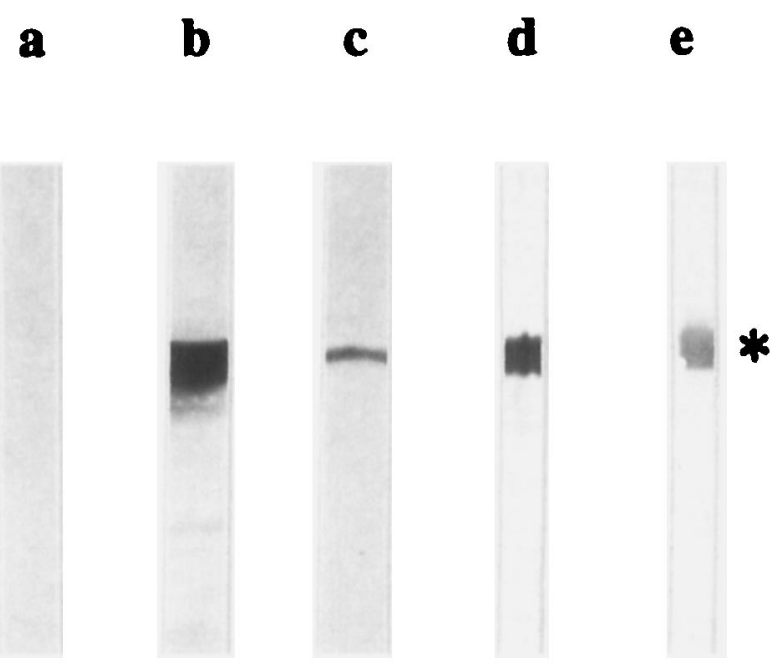

Fig. 1. Immunoblots of rabbit antiserum against meningococcal protein extracts. a, R-70 antiserum (absorbed with $E$. coli lysate) against total protein extracts of $E$. coli XL1 Blue; b, as (a) but after transformation with plasmid pSK34a; c, anti-Men-E2p antiserum against OMV extracts of iron-sufficient $N$. meningitidis strain $\mathrm{SD}$; d, purified Men-E2p probed with antiserum against whole $A$. vinelandii $\mathrm{E} 2 \mathrm{p}$; e, purified Men-E2p probed with antiserum against the lipoyl domain of $A$. vinelandii E2p. ${ }^{*}$ c. $70 \mathrm{kDa}$.

representative recombinant plasmids (pSK18a and pSK34a) were chosen and both strands of their cloned DNA were sequenced with an Applied Biosystems 373A DNA Sequencer. Oligonucleotide primers were synthesised by an Applied Biosystems 381A DNA Synthesiser and used for the sequencing. These primers were: M13 Forward, TTG TAA AAC GAC GGC CAG TG and M13 Reverse, CAC ACA GGA AAC AGC TAT GAC C.

\section{Enzyme assays and Men-E2p characterisation}

Plasmid pSK34a was transformed into competent TG2 $E$. coli cells, and ampicillin-resistant colonies were isolated, grown, harvested, sonicated and examined for the presence of dihydrolipoamide transacetylase activity by previously described methods [15]. At maximum expression level, the endogenous transacetylase activity was $1-2 \%$ of total activity measured in cell extracts obtained from empty vector transformed cells [15]. This was assayed spectrophotometrically at $240 \mathrm{~nm}$ and $25^{\circ} \mathrm{C}$ in a coupled assay with phosphotransacetylase (Sigma), measuring the formation of S-acetyldihydrolipoamide as described by Schwartz and Reed [16]. Dihydrolipoamide was prepared from DL-lipoamide as described by Reed et al. [17]. Protein concentrations were estimated with the microbiuret method [18] after precipitation with deoxycholic acid and trichloroacetic acid [19]. Bovine serum albumin was used as the standard.

\section{Isolation of expressed Men-E2p from $E$. coli}

A single colony of $E$. coli TG2 (pSK34a) was picked from a yeast-tryptone (YT) agar plate containing 
>-- ORF1 - - >

$\begin{array}{llllllllllllllllllll}D & R & Y & N & V & A & V & A & A & L & A & A & L & A & E & Q & G\end{array}$

1 GAT CGC TAC AAC GTT GCC GTG GCC GCA TTG GCC GCA TTG GCG GAA CAA GGC

$\begin{array}{lllllllllllllllll}K & V & S & K & E & T & V & Q & Q & A & I & E & K & Y & G & I & K\end{array}$

52 AAA GTC AGC AAA GAA ACC GTT CAA CAA GCC ATT GAG AAA TAC GGC ATC AAA

$$
\begin{array}{lllllllllll}
A & D & S & A & P & S & W & K & R & \text { Stop }
\end{array}
$$

103 GCC GAT TCA GCT CCT AGC TGG AAA CGC TGA TTGATGTTTCAGACGGCCTGTTTGCCC

159 CATTCCGACATCAGGCCGTCTGAAAACCGAATGCCCGAATGGTTTGAGCAGACAAACCGTACCGATG

227 CCGCCTGAAGCAGCTTTCA GAC GGC ATC CAA TTG AAA AAG ATT AAA GGA ACT CAA

$>--$ ORF2 --->

$\begin{array}{llllllllllllllllll}M & S & I & V & E & I & K & V & P & D & I & G & G & H & E & N & V\end{array}$

282 ATG AGT ATC GTA GAA ATC AAA GTC CCC GAT ATC GGC GGT CAC GAA AAC GTC

$\begin{array}{lllllllllllllllll}D & I & I & A & V & E & V & K & A & G & D & T & I & A & V & D & D\end{array}$

333 GAC ATC ATC GCC GTA GAA GTT AAA GCG GGC GAC ACC ATC GCC GTT GAC GAC

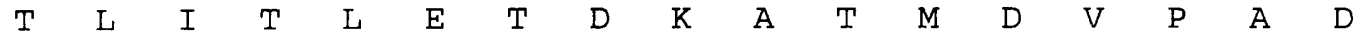

384 ACC CTG ATT ACA CTG GAA ACC GAC AAA GCC ACG ATG GAT GTG CCT GCC GAT $\begin{array}{lllllllllllllllll}A & A & G & V & V & K & E & V & K & V & K & V & G & D & K & I & S\end{array}$ 435 GCG GCC GGT GTC GTG AAA GAA GTA AAA GTC AAA GTC GGC GAC AAA ATC TCC $\begin{array}{lllllllllllllllll}E & G & G & V & I & L & T & V & E & T & G & A & A & A & A & E & A\end{array}$ 486 GAA GGC GGC GTA ATT CTG ACC GTT GAA ACC GGT GCC GCC GCC GCC GAA GCC $\begin{array}{lllllllllllllllll}A & P & A & A & A & E & A & Q & P & E & P & A & A & A & P & A & A\end{array}$ 537 GCC CCG GCT GCT GCC GAA GCA CAA CCT GAA CCT GCT GCC GCA CCC GCT GCC $\begin{array}{lllllllllllllllll}A & G & G & A & T & V & Q & V & A & V & P & D & I & G & G & H & T\end{array}$ 588 GCA GGC GGT GCA ACC GTT CAA GTA GCC GTT CCC GAT ATC GGC GGC CAT ACC $\begin{array}{lllllllllllllllll}D & V & D & V & I & A & V & E & I & K & V & G & D & T & V & A & E\end{array}$ 639 GAT GTG GAT GTA ATC GCC GTT GAA ATC AAA GTG GGC GAC ACC GTT GCC GAA $\begin{array}{lllllllllllllllll}\mathrm{D} & \mathrm{D} & \mathrm{T} & \mathrm{L} & \mathrm{I} & \mathrm{T} & \mathrm{L} & \mathrm{E} & \mathrm{T} & \mathrm{D} & \mathrm{K} & \mathrm{A} & \mathrm{T} & \mathrm{M} & \mathrm{D} & \mathrm{V} & \mathrm{P}\end{array}$ 690 GAC GAC ACG CTG ATT ACT TTG GAA ACC GAT AAA GCG ACA ATG GAC GTA CCT $\begin{array}{lllllllllllllllll}C & T & A & A & G & V & V & K & A & V & F & L & K & V & G & D & K\end{array}$ 741 TGT ACC GCT GCC GGT GTC GTT AAA GCC GTA TTC TTA AAA GTC GGC GAC AAA $\begin{array}{lllllllllllllllll}V & S & E & G & S & A & I & I & E & V & E & T & V & G & S & A & A\end{array}$ 792 GTA TCC GAA GGC TCT GCC ATT ATC GAA GTA GAA ACC GTC GGC TCT GCC GCA $\begin{array}{lllllllllllllllll}A & A & P & A & Q & A & A & Q & A & A & A & P & A & A & A & P & P\end{array}$ 842 GCA GCC CCT GCT CAA GCC GCT CAA GCT GCC GCA CCG GCT GCC GCT CCG CCT $\begin{array}{lllllllllllllllll}\mathrm{P} & \mathrm{T} & \mathrm{A} & \mathrm{A} & \mathrm{A} & \mathrm{A} & \mathrm{P} & \mathrm{A} & \mathrm{A} & \mathrm{A} & \mathrm{P} & \mathrm{A} & \mathrm{P} & \mathrm{S} & \mathrm{A} & \mathrm{P} & \mathrm{A}\end{array}$

893 CCG ACT GCT GCC GCC GCA CCC GCC GCC GCG CCT GCA CCT TCT GCA CCT GCC $\begin{array}{lllllllllllllllll}A & A & K & I & D & E & A & A & F & A & K & A & H & A & G & P & S\end{array}$ 944 GCT GCC AAA ATC GAC GAG GCC GCT TTC GCC AAA GCA CAC GCC GGT CCT TCC $\begin{array}{lllllllllllllllll}A & R & K & L & A & R & E & L & G & V & D & L & G & Q & V & K & G\end{array}$ 995 GCA CGC AAA CTG GCG CGC GAA TTG GGC GTG GAT TTG GGC CAA GTC AAA GGC $\begin{array}{lllllllllllllllll}T & G & L & K & G & R & I & M & G & D & D & I & K & A & F & V & K\end{array}$ 1046 ACC GGC TTG AAA GGC CGT ATC ATG GGC GAC GAC ATC AAA GCC TTT GTG AAA $\begin{array}{lllllllllllllllll}S & V & M & Q & G & G & A & A & K & P & A & A & A & S & A & S & L\end{array}$ 1097 TCC GTG ATG CAG GGC GGC GCG GCA AAA CCT GCC GCA GCC AGC GCA TCT TTG

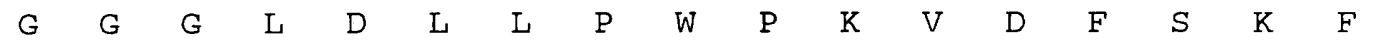
1148 GGC GGC GGT CTG GAC TTA CTG CCG TGG CCT AAA GTG GAC TTC TCC AAA TTC $\begin{array}{lllllllllllllllll}G & N & V & E & V & K & E & L & S & R & I & K & K & I & S & G & Q\end{array}$

1199 GGC AAT GTC GAA GTT AAA GAA TTG TCC CGC ATT AAG AAA ATT TCC GGT CAA $\begin{array}{llllllllllllllllll}N & L & S & R & N & W & V & V & I & P & H & V & T & V & H & E & E\end{array}$

1250 AAC CTG TCC CGC AAC TGG GTT GTG ATT CCC CAC GTT ACC GTA CAC GAA GAA $\begin{array}{lllllllllllllllll}A & D & M & T & E & L & E & E & F & R & K & Q & L & N & K & E & W\end{array}$ 1301 GCG GAC ATG ACC GAG CTG GAA GAA TTC CGC AAA CAG CTG AAC AAA GAA TGG $\begin{array}{llllllllllllllllll}E & R & E & G & V & K & L & S & P & L & A & F & I & I & K & A & S\end{array}$ 1352 GAA CGC GAA GGC GTG AAA CTG TCC CCG TTG GCG TTC ATC ATC AAA GCC TCT $\begin{array}{lllllllllllllllll}V & S & A & L & K & A & F & P & E & F & N & A & S & L & D & G & D\end{array}$ 1403 GTT TCC GCG TTG AAA GCA TTC CCC GAA TTC AAC GCC TCA CTG GAC GGC GAC $\begin{array}{lllllllllllllllll}N & L & V & L & K & N & Y & F & N & I & G & F & A & A & D & T & P\end{array}$ 1454 AAC CTG GTG CTG AAA AAC TAC TTC AAC ATC GGT TTC GCA GCC GAT ACG CCG $\begin{array}{lllllllllllllllll}N & G & L & V & V & P & V & I & K & D & V & D & Q & K & G & L & K\end{array}$

Fig. 2. The sequence data for cloned meningococcal DNA of pSK34a and the deduced amino-acid sequence of the ORFs. A putative ribosome-binding site for ORF2 is underlined. Stop = translational stop codon. 
$\begin{array}{lllllllllllllllll}\mathrm{Q} & \mathrm{I} & \mathrm{S} & \mathrm{Q} & \mathrm{E} & \mathrm{L} & \mathrm{T} & \mathrm{E} & \mathrm{L} & \mathrm{S} & \mathrm{K} & \mathrm{K} & \mathrm{A} & \mathrm{R} & \mathrm{E} & \mathrm{G} & \mathrm{K}\end{array}$ 1556 CAA ATC AGC CAA GAA TTG ACC GAA TTG TCC AAA AAA GCC CGT GAA GGC AAG $\begin{array}{lllllllllllllllll}L & K & P & Q & E & M & Q & G & A & C & F & T & I & S & S & L & G\end{array}$ 1607 CTC AAA CCG CAA GAA ATG CAA GGC GCG TGC TTT ACC ATT TCC AGC TTA GGC

$\begin{array}{lllllllllllllllll}G & I & G & G & T & G & F & T & P & I & V & N & A & P & E & V & A\end{array}$ 1658 GGC ATC GGC GGC ACA GGC TTC ACG CCA ATT GTG AAC GCT CCC GAA GTC GCC

1709 ATC TTG GGC GTG TGC AAA TCC CAA ATC AAA CCT GTT TGG AAC GGC AAA GAG $\begin{array}{lllllllllllllllll}F & A & P & R & L & M & C & P & L & S & L & S & F & D & H & R & V\end{array}$ 1760 TTT GCC CCG CGC CTG ATG TGC CCG TTG AGC CTG TCC TTC GAC CAC CGT GTC $\begin{array}{llllllllllllllllllllllll}I & D & G & A & A & G & M & R & F & T & V & F & L & A & K & L & L\end{array}$ 1811 ATC GAC GGT GCG GCC GGT ATG CGC TTC ACC GTA TTC TTG GCG AAG CTG TTG $\begin{array}{llllllllll}K & D & F & R & R & I & T & L & \text { stop }\end{array}$

1861 AAA GAC TTC CGC CGC ATT ACC TTA TAA AAT AAA ACA TCC CTC TCA AGC AGT

1912 CTGATAATGTTGGATTGCTTGAGATTGATGAGTAATGGTGTTAAATTCAACCTTTAAATTAATAA

\section{>-- ORF3 --D}

$\begin{array}{lllllllllllllllll}L & M & G & N & F & L & Y & R & G & I & S & C & Q & Q & D & E & Q\end{array}$ 1980 CTT ATG GGA AAT TTC TTA TAT AGA GGC ATT AGT TGC CAA CAA GAT GAG CAA $\begin{array}{lllllllllllllllll}N & N & G & Q & L & K & P & K & G & N & K & A & E & V & A & I & R\end{array}$ 2031 AAT AAT GGA CAG TTA AAA CCT AAA GGT AAT AAA GCT GAA GTT GCA ATT CGT $\begin{array}{lllllllllllllllll}Y & D & G & K & F & K & Y & D & G & K & A & T & H & G & P & S & V\end{array}$ 2082 TAT GAT GGT AAG TTT AAA TAT GAT GGT AAA GCT ACA CAT GGT CCA AGT GTG $\begin{array}{lllllllllllllllll}K & N & A & V & Y & A & H & Q & I & E & T & G & L & Y & D & G & C\end{array}$ 2133 AAG AAT GCA GTT TAC GCC CAT CAA ATT GAA ACA GGT CTA TAT GAC GGA TGT

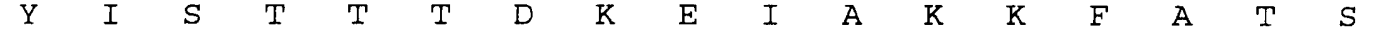
2184 TAT ATA TCT ACG ACA ACA GAC AAG GAA ATT GCC AAG AAA TTT GCA ACA AGT $\begin{array}{lllllllllllllllll}S & G & I & E & N & G & Y & I & Y & V & L & N & R & D & L & F & G\end{array}$ 2235 TCC GGC ATC GAA AAT GGC TAT ATA TAT GTT TTA AAT AGG GAT TTG TTT GGT $\begin{array}{lllllllllllllllll}Q & Y & S & I & F & E & Y & E & V & E & H & P & E & N & P & N & E\end{array}$ 2286 CAA TAT TCT ATT TTT GAA TAT GAG GTT GAA CAT CCA GAA AAC CCA AAT GAG $\begin{array}{lllllllllllllllll}K & E & V & T & I & R & A & E & D & C & G & C & I & P & E & E & V\end{array}$ 2337 AAG GAA GTA ACA ATC AGA GCT GAA GAT TGT GGC TGT ATT CCT GAA GAA GTG $\begin{array}{lllllllllll}I & I & A & K & E & L & I & E & I & N & \text { stop }\end{array}$

2388 ATT ATT GCT AAA GAG TTG ATA GAA ATT AAC TAA GTT GA

\section{$>--$ ORF4 --->}

$\begin{array}{lllllllllllllllll}K & V & N & I & M & A & L & V & E & \text { L } & K & V & P & D & I & G & G\end{array}$ 2426 AAG GTC AAT ATA ATG GCT TTA GTT GAA TTG AAA GTG CCC GAC ATT GGC GGA $\begin{array}{lllllllllllllllll}\mathrm{H} & \mathrm{E} & \mathrm{N} & \mathrm{V} & \mathrm{D} & \mathrm{I} & \mathrm{I} & \mathrm{A} & \mathrm{V} & \mathrm{E} & \mathrm{V} & \mathrm{N} & \mathrm{V} & \mathrm{G} & \mathrm{D} & \mathrm{T} & \mathrm{I}\end{array}$

2477 CAC GAA AAT GTA GAT ATT ATC GCG GTT GAA GTA AAC GTG GGC GAC ACT ATT $\begin{array}{lllllllllllllllll}A & V & D & D & T & L & I & T & L & E & T & D & K & A & T & M & D\end{array}$

2528 GCT GTG GAC GAT ACC CTG ATT ACT TTG GAA ACC GAT AAA GCG ACT ATG GAC $\begin{array}{lllllllllllllllll}V & P & A & E & V & A & G & V & V & K & E & V & K & V & K & V & G\end{array}$ 2579 GTA CCT GCT GAA GTT GCA GGC GTA GTC AAA GAA GTT AAA GTT AAA GTC GGC $\begin{array}{ccccccccccccccccc}\text { D } & \text { K } & \text { I } & \text { S } & \text { E } & \text { G } & \text { G } & \text { L } & \text { I } & \text { V } & \text { V } & \text { V } & \text { E } & \text { A } & \text { E } & \text { G } & \text { T } \\ \text { GAC } & \text { AAA } & \text { ATC } & \text { TCT } & \text { GAA } & \text { GGT } & \text { GGT } & \text { TTG } & \text { ATT } & \text { GTC } & \text { GTC } & \text { GTT } & \text { GAA } & \text { GCT } & \text { GAA } & \text { GGC } & \text { ACG }\end{array}$

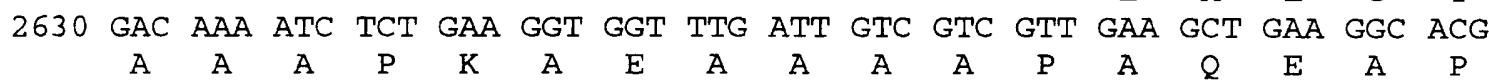
2681 GCA GCC GCT CCT AAA GCC GAA GCG GCT GCC GCC CCG GCG CAA GAA GCC CCT $\begin{array}{lllllllllllllllll}K & A & A & A & P & A & P & Q & A & A & Q & F & G & G & S & A & D\end{array}$

2732 AAA GCT GCC GCT CCT GCT CCG CAA GCC GCG CAA TTC GGC GGT TCT GCC GAT $\begin{array}{lllllllllllllllll}A & E & Y & D & V & V & V & L & G & G & G & P & G & G & Y & S & A\end{array}$

2783 GCC GAG TAC GAC GTG GTC GTA TTG GGT GGC GGT CCC GGC GGT TAC TCC GCT $\begin{array}{lllllllllllllllll}A & F & A & A & A & D & E & G & L & K & V & A & I & V & E & R & Y\end{array}$ 2834 GCA TTT GCC GCT GCC GAT GAA GGC TTG AAA GTC GCC ATC GTC GAA CGT TAC $\begin{array}{lllllllllllllllll}\text { K } & \text { T } & \text { L } & \text { G } & \text { G } & \text { V } & \text { C } & \text { L } & \text { N } & \text { V } & \text { G } & \text { C } & \text { I } & \text { P } & S & \text { K } & \text { A } \\ \end{array}$

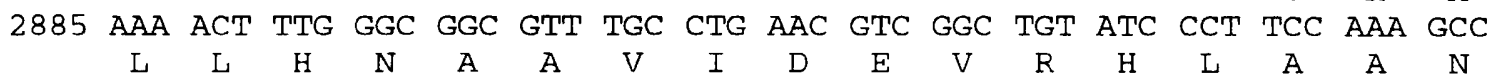
2936 TTG TTG CAC AAT GCC GCC GTT ATC GAC GAA GTG CGC CAC TTG GCT GCC AAC $\begin{array}{lllllllllllllllll}G & I & K & Y & P & E & P & E & L & D & I & D & M & L & R & A & Y\end{array}$ 2987 GGT ATC AAA TAC CCC GAG CCG GAA CTC GAC ATC GAT ATG CTT CGC GCC TAC 
ampicillin $50 \mathrm{mg} / \mathrm{L}$ and grown overnight at $37^{\circ} \mathrm{C}$ in $10 \mathrm{ml}$ of YT broth containing ampicillin $75 \mathrm{mg} / \mathrm{L}$. A $100-\mu 1$ sample of this culture was used to inoculate $10 \mathrm{ml}$ of the same medium which was then incubated at $37^{\circ} \mathrm{C}$ for $8 \mathrm{~h}$. Each of six 2-L flasks with $500 \mathrm{ml}$ of YT containing ampicillin $75 \mathrm{mg} / \mathrm{L}$ and IPTG $20 \mathrm{mg} / \mathrm{L}$ were inoculated with $0.5 \mathrm{ml}$ of this starter culture and incubated for $16 \mathrm{~h}$ at $37^{\circ} \mathrm{C}$ in a controlled environment shaker at $300 \mathrm{rpm}$. Cells $(5 \mathrm{~g})$ were harvested and used for isolation of Men-E2p. The cells were suspended in $27 \mathrm{ml}$ of $50 \mathrm{mM}$ potassium phosphate buffer containing $2 \mathrm{mM}$ EDTA, $0.1 \mathrm{mM}$ phenylmethane sulphonyl fluoride (PMSF) (Merck) and $1 \mathrm{mM}$ benzamidine, $\mathrm{pH} \mathrm{7.0,} \mathrm{and}$ disrupted with a French press applying two cycles at 18000 psi. After centrifugation for $1 \mathrm{~h}$ at $14000 \mathrm{~g}$, the supernate was adjusted to a protamine sulphate final concentration of $0.27 \% \mathrm{w} / \mathrm{v}$, in which Men-E2p remained soluble. The turbid solution was centrifuged for $45 \mathrm{~min}$ at $14000 \mathrm{~g}$ and the clear supernate was concentrated to $5 \mathrm{ml}$ by ultrafiltration (Amicon YM100, Grace Amicon, Essebaan, The Netherlands). The concentrate was then applied to a Sephacryl S-400HR column $(2.4 \times 100 \mathrm{~cm})$ (Pharmacia), equilibrated with $50 \mathrm{mM}$ potassium phosphate buffer containing $0.5 \mathrm{mM}$ EDTA, $0.1 \mathrm{mM}$ PMSF and $1 \mathrm{mM}$ benzamidine, $\mathrm{pH}$ 7.0. Enzymically active fractions were analysed on SDSPAGE and those with pure Men-E2p contents were pooled. After concentration to $3 \mathrm{ml}$ by ultrafiltration (Amicon YM100) the protein was stored in liquid nitrogen.

For immunisation, $1 \mathrm{mg}$ of purified Men-E2p was electrophoresed on a preparative SDS-polyacrylamide gel. The gel was then stained for $1 \mathrm{~min}$ with Coomassie Brilliant Blue R250, and the protein band of interest was excised and recovered from the gel slice by electroelution in $2.5 \mathrm{mM}$ Tris- $\mathrm{HCl}, 20 \mathrm{mM}$ glycine, $0.35 \mathrm{~mm}$ SDS.

\section{Limited proteolysis and $N$-terminal sequence analysis}

Limited proteolysis was performed on Men-E2p in $50 \mathrm{ml}$ of potassium phosphate buffer containing $0.5 \mathrm{mM}$ EDTA, pH 7, with trypsin (Sigma) $0.1 \%$ w/w at $4^{\circ} \mathrm{C}$ for $60 \mathrm{~min}$. The reaction was stopped by the addition of $1 \mathrm{mM}$ PMSF and samples were subjected to SDSPAGE.

Purified Men-E2p (400 $\mu \mathrm{g})$ was blotted from SDSpolyacrylamide gels on to Immobilon (Millipore, Watford) and used for N-terminal amino-acid analysis, with an Applied Biosystems 475 Protein Sequencer.

\section{Results}

Cloning and sequence analysis

Screening of c. 50000 plaques for specific protein expression identified 100 positive plaques. Most plaques were recognised by the R-70 antiserum under both native and denatured conditions. Twenty-five of the most strongly positive plaques were rescued and analysed by immunoblotting for protein expression before and after IPTG-induction. Of the examined plasmids, pSK34a (3.1-kb insert) showed the highest level of expression of cloned protein of $c$. $70 \mathrm{kDa}$ (Fig. 1, lane b). This expression was not affected by IPTG stimulation. Plasmid pSK18a (1.5-kb insert) also showed strong expression of a protein reactive with $\mathrm{R}$ 70 , but with lower molecular mass (c. $65 \mathrm{kDa}$, not shown).

Both plasmids were restriction-mapped and both of their strands were fully sequenced (Fig. 2), EMBL accession number X82637. The main features of the analysed DNA sequence are shown in Fig. 3. Four open reading frames (ORFs) were predicted from the sequence analysis. The deduced amino-acid sequence of ORF1, ORF2 and ORF4 showed a high degree of homology with the amino-acid sequences of $E$. coli pyruvate dehydrogenase (E1p), dihydrolipoyl acetyltransferase (E2p) and dihydrolipoyl dehydrogenase (E3), respectively. These are components of the pyruvate dehydrogenase complex (PDHC). The deduced sequence of ORF2 showed amino-acid identity with the E2 component of PDHC, and the 2oxoglutarate dehydrogenase complexes of a number of prokaryotic and eukaryotic cells, including $E$. coli, Azotobacter vinelandii, Alcaligenes eutrophus [20-22], yeasts, rats and man. Fig. 4 shows sequence alignment of meningococcal E2p (Men-E2p) with the E2p of PDHC of the other three gram-negative species.

ORF1 and ORF4 were incomplete genes, being part of larger coding regions. Indeed, subsequent sequence data (not published) confirmed that ORF1 is part of an 887 amino-acid long reading frame (included within X82637). The deduced sequence of ORF4 was almost identical ( $>99 \%$ homology) to the N-terminal sequence of the previously sequenced meningococcal OMP64 (Accession No. X77920) [23]. However, ORF3 failed to show significant homology with any described DNA or protein sequence. The most closely related protein was yeast mitochondrial precursor proteins import receptor and heat shock protein homologue (with c. 90 amino acid overlap, $22 \%$ homology). The DNA sequence of ORF3 showed homology with a number of unrelated genes, such as a region of the replication origin of Bacillus subtilis and eukaryotic ATP synthase gamma-subunit. An ORF of this size and position (between E2p and E3 components of PDHC) is thus far only found in the gene cluster encoding PDHC of Al. eutrophus [22]. Unlike the latter, the base composition of ORF3 deviates considerably from that of the other ORFs.

Finally, the deduced sequence of none of the ORFs within pSK34a showed significant homology with the 

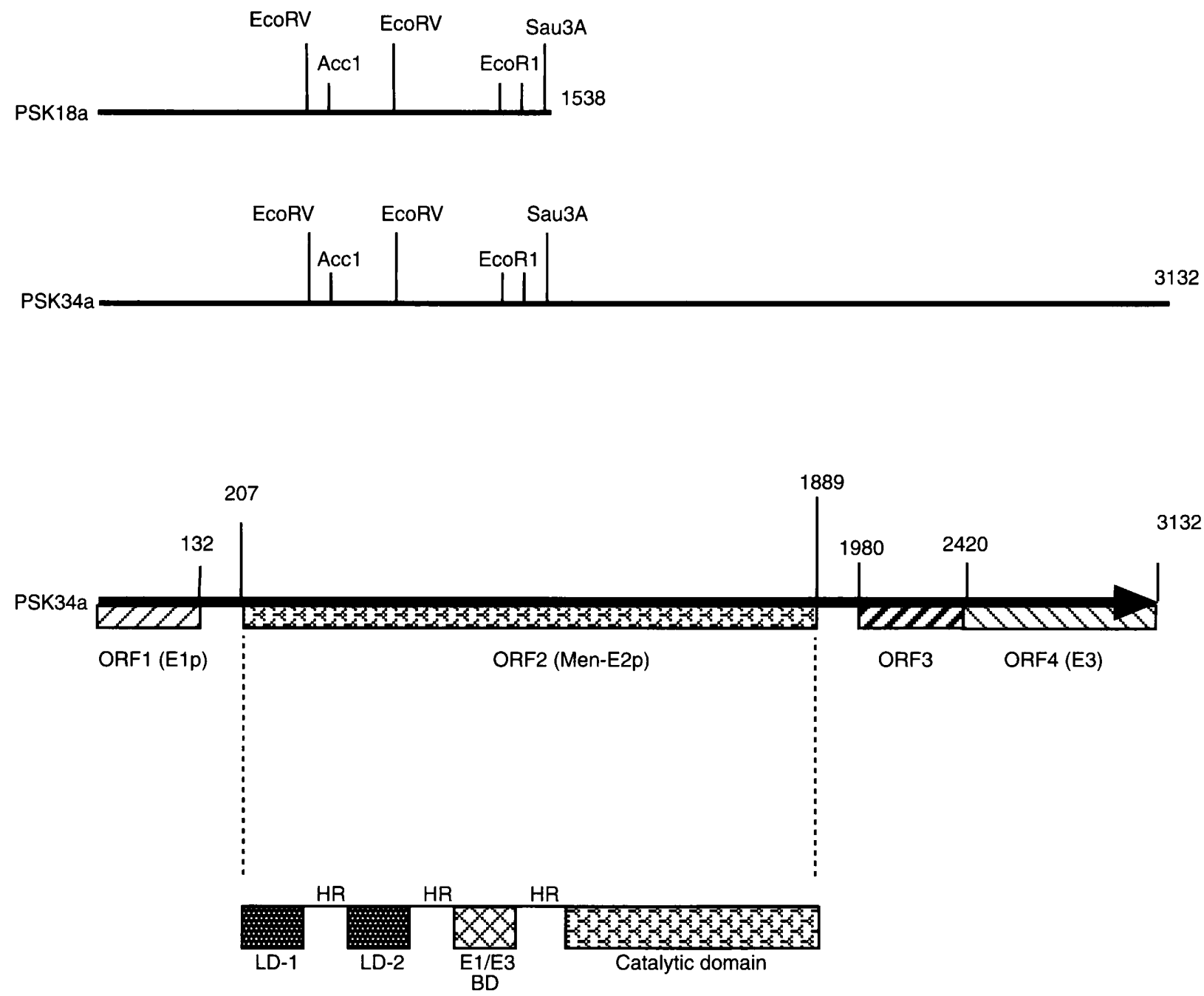

Fig. 3. Schematic representation of a partial restriction map and computer-predicted features of the cloned DNA of pSK18a and pSK34a plasmids. ORF, open reading frame. Numbers indicate distance (in bp) from the $5^{\prime}$ end. The domain structure of Men-E2p, as deduced from the sequence homology data with other E2 sequences, is also shown. LD-1 and LD-2, lipoyl domains 1 and 2; BD, E1/E3 binding domain; HR, hinge region.

recently published sequences of meningococal or gonococcal FrpB protein $[8,24]$.

\section{Functional characterisation of meningococcal E2p (Men-E2p)}

Plasmid pSK34a, which contained the complete ORF2, was chosen for expression of the ORF2 product (Men$\mathrm{E} 2 \mathrm{p}$ ) in $E$. coli TG2. Men-E2p was expressed and purified and its properties were examined.

The E2p activity of the Men-E2p-expressing E. coli
TG2 was low in the exponential growth phase (at $8 \mathrm{~h}$ growth); however, it increased steadily towards the end-log and stationary phase and was optimal after $16 \mathrm{~h}$. Therefore, cells were harvested at this stage, when the E2p activity was $4 \mathrm{U} / \mathrm{mg}$ (Table 1). This is similar to that of $A$. vinelandii E2p expressed in the same $E$. coli strain $(4.4 \mathrm{U} / \mathrm{mg})$ [25], except that the cell yield was only $50 \%$ for Men-E2p.

When examined by SDS-PAGE, the Men-E2p-expressing E. coli TG2 showed a strongly stained protein band at c. $70 \mathrm{kDa}$ (Fig. 5), as expected for an E2p possessing two lipoyl domains. The corresponding

Table 1. Purification of meningococcal E2p from E. coli TG2 (pSK34a)

\begin{tabular}{lccccc}
\hline Sample & $\begin{array}{c}\text { Volume } \\
(\mathrm{ml})\end{array}$ & $\begin{array}{c}\text { Protein } \\
\text { content } \\
(\mathrm{mg})\end{array}$ & $\begin{array}{c}\text { Specific } \\
\text { activity } \\
(\mathrm{U} / \mathrm{mg})\end{array}$ & $\begin{array}{c}\text { Total } \\
\text { activity } \\
(\mathrm{U})\end{array}$ & $\begin{array}{c}\text { Yield } \\
(\%)\end{array}$ \\
\hline Crude extract & 27 & 483 & 4.0 & 1932 & 100 \\
Protamine sulphate & 29 & 268 & 6.8 & 1816 & 94 \\
S400HR eluate & 3 & 21 & 58.2 & 1243 & 64 \\
\hline
\end{tabular}




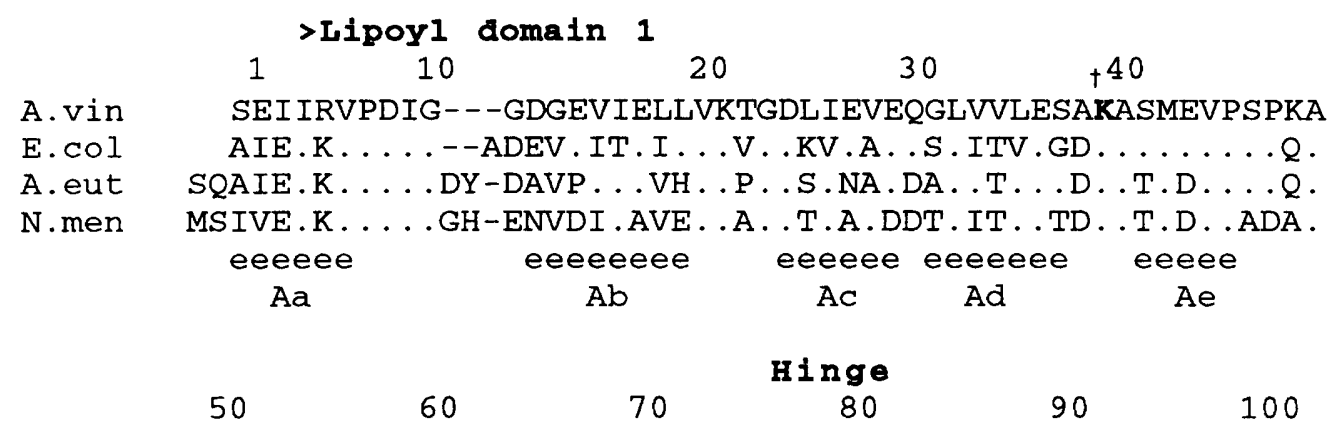

A. vin E.col

A. eut

$\mathrm{N}$. men

A. vin E.col A. eut N.men

A. vin E.col A. eut N.men

A.vin E. $c 01$

A. eut N.men

A.vin E.col

A. eut

$\mathrm{N}$. men

A. vin

E.col

A. eut

N.men

E.col

A. eut

GVVKSVSVKLGDKLKEGDA I IELEPAAGAAAAPAEAAAVPAAPTQAVDEAEA . I . . EIK . SV . . TQT . AL . MIFDS . D . . . D. APAQ . EEKKEAAP . AAP . A . ....D.RI.V . . NVS . SVLVM . A. NEP . . . . . . A . PAAA. PAP . P . ....E.K..V...IS . GV.LTV.TG.A..E.APA. EAQPE.AA.PAA.GG eeeeee eeeee eeeee

Af

Ag Ah

$\begin{array}{llccc}\text { <Lipoy1 domain } & 2 & & \\ 110 & 120 & 130 & 140 & 150\end{array}$
PSPGASATPAPAAA-SQEVRVPDIGSAGKARVIEVLVKAGDQVQAEQSLIVL A-- - - .-- AKD.N. . . . -SDEVE.T.I. . V. .K.E. . . . TV . AAAPA . A . AGGGGTI . K . . . . DYDAVP . . . . . . . . TIN . . DAVVT . A- - . . - - TVQ . A . . . GHTDVD. . A.EI.V. . . AEDDT . T .
$+160$
170
180
190
200

ESDKASMEIPSPASGVVESVAIQLNAEVGTGDLILTLRTTGAQAQPTAPAAA .G. . . . .V.A.FA.T.KEIKVNVGDK.S . S . MVFEVA. QAGAAAPA.KQ .... T.DV . . QG . . KE.KVKVGDN.AE.T.L.I.EGAA.A.A.A.A. . .T...T.DV.CT.A...KA.FLKVGDK.SE.SA.IEVE.V.SA.PAP.Q. .Q

$210 \quad 220$

AAASPAPAPLAPAAAGE. . PA. APAP . AG . P. AAASGTGRSTCCRAGRRWRNRQGR ... PA. AP . PTA. . . PAAAPAPSAPAAAKIDEAAFAKA $\ldots \ldots$

$<$ Lipoy 1 domain 3

$230 \quad 240 \quad 250 \quad 260_{+} \quad 270$
PQEVKVPDIGSAGKARVIEVLVKAGDQVQAEQSLIVLESDKASMEIPSPAAG VK..N.....GDEVE.T..M..V..K.A.....TV.G.....V.A.F. .

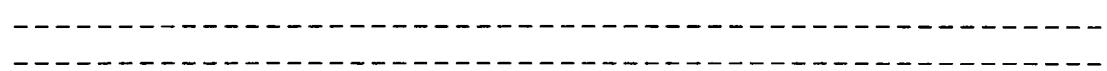

$280 \quad 290 \quad 300$

VVESVAVQLNAEVGTGDQILTLRVAGAAPSGPRARGSPGQAAAAAAAAPAPA . . KELK . NVGDK . K . . SL . MIFE . E . . . AAA . . KQEAAAP . P . . K . EAPA .

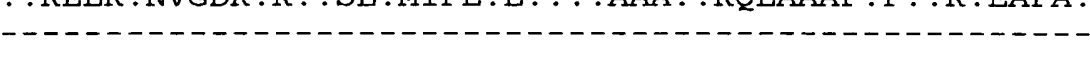

$330 \quad 340 \quad$ P1/E3 3 Binding domain

PVGAPSRNGAKV--.---HAGPAVRQLAREFGVELAAINSTGPRGRILKED APAAKAEGKSEFAENDAYV . T.LI.RI . . . . . N . KVKG . RK . . . R.E A . . . . .

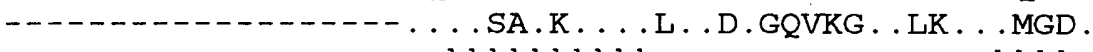
eehhhhhhhhhheee hhhh

$\mathrm{Ba} \quad \mathrm{BH} 1 \mathrm{Bb} \quad \mathrm{BH} 2$

Fig. 4. Structure-based sequence alignment of E2p from A. vinelandii (A.vin), E. coli (E.col), Al. eutrophus (A.eut) and $N$. meningitidis (N.men). The structural comparison of the first lipoyl domain (A) is based on the NMR data obtained for the $A$. vinelandii N-terminal lipoyl domain [30]. For the E1/E3 binding domain (B), the NMR data of the E3 binding domain from E. coli E2o [29] have been used. The structural comparison of the catalytic domain (C) is based on the co-ordinates of the catalytic domain from $A$. vinelandii E2p [28]. Secondary structure is indicated by the letters $\mathrm{h}$ (helix) and e (sheet) for each of these domains. T The catalytically important residues. ${ }^{*}$ The residues involved in intertrimer interaction of the catalytic domain. 


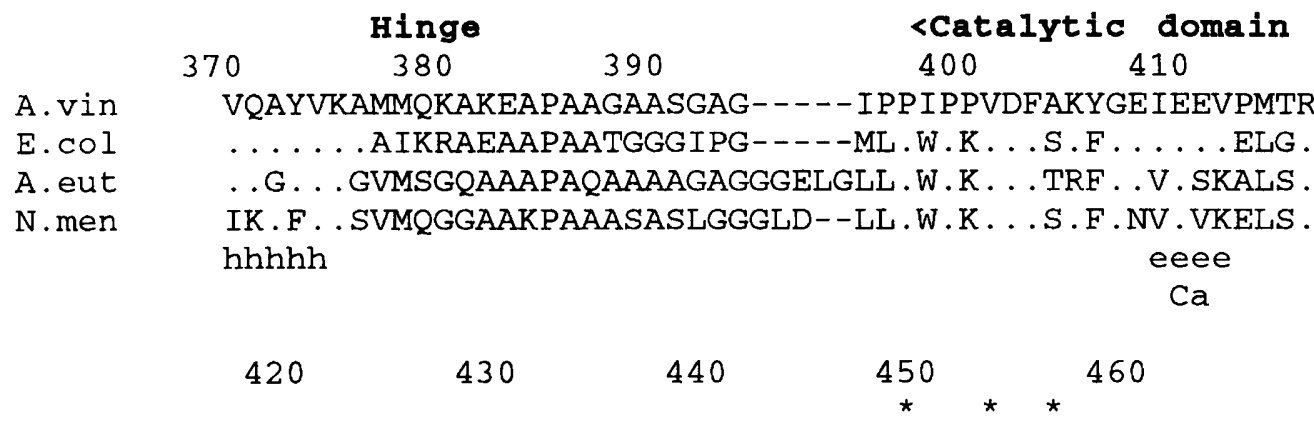

A. vin

E.col

A. eut

N.men

A. vin
E.col
A. eut
N. men

A.vin

E. col

A. eut

N.men

A. vin

E.col

A. eut

N.men

A. vin

E.col

A. eut

N.men
LMOIGATNLHRSWLNVPHVTQFESADITELEAFRVAQKAVAEKAG--VKLTV IQK.SGA . S.N.VMI . ..H.DKT . . . . . KQ.NEE.A.RKLD . I . P IKK. SGA . . . N.VMI . NHD . . . E . . . . . . . LQLNKEN.S. - - I.V.M IKK. SGQ . S.N.VVI.VH . . . EA.M . . . E . .KQLNKEW.RE . - . . . SP

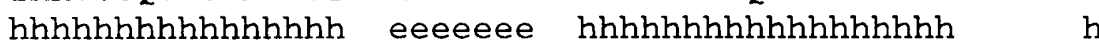
$\mathrm{CH} 1$ $\mathrm{Cb}$ $\mathrm{CH} 2$

$\begin{array}{llll}470 & 480 & 490 & 500\end{array}$

LPLLLKACAYLLKELPDFNSSLAPSGQALIRKKYVHIGFAVDTPDGLLVPV VVFIM. .V.AA.EQM.R . . . . SED . R.TL . . IN . V . . . . . .V. . . . AFMI . TVAA . KF . N . A . DGDN-- .VL . . FN . . . A . . N . . . . . .AFII . .SVSA . AF .E. . A . DGDN--.VLKN. FN . . . A . . N . .V . . . hhhhhhhhhhhhhh eee eeeee eeeee eeee $\mathrm{CH} 3$ $\mathrm{CC}$ $\mathrm{cd}$ cf

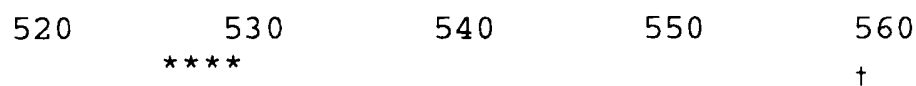

IRNVDQKSLLQLAAEAAELAEKARSKKLGADAMQGACFTISSLGH IGGTAF

FKD.NK.GIIE.SR . LMTISK . . DG . T.GE . .G . . . . I.GL . . . .

.KDA.K.GV.EISQ.MS . . KL . . DG . KP.Q . . G. . . . . . GL . . Y . .KD . . . G.K. ISQ.LT. .SK . . EG . KPQE . . . . . . . . . . . . G. ee hhhhhhhhhhhhhhh eeee eee $\mathrm{CH} 4$ $\mathrm{Cg} \quad \mathrm{Ch}$

$\begin{array}{llll}570 & 580 & 590 & 600\end{array}$
TP IVNAPEVAILGVSKASMQPVWDGKAFQPRLMLPLSLSYDHRVINGAAAA

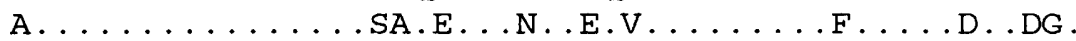

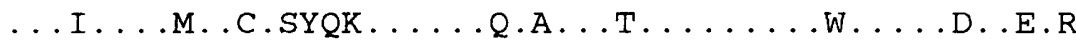

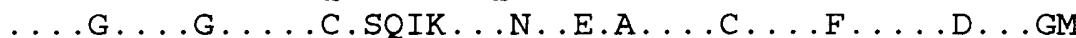
eee eeeee eeeeeee hhhh $\mathrm{Ci}$

$\mathrm{cj}$ CH5 620

630

RFTKRLGDLLADIRAILL ..ITIINNT.S. . RLVM FN. $-Y F . Q$. . F.RI. ..VV.AK..K.F.RIT. hhohhhhhhhh hhhhh

$\mathrm{CH} 6$

Fig. 4. (continued).

host proteins, E2o containing a single lipoyl domain and E2p containing three lipoyl domains, show bands in SDS gels at $c .56 \mathrm{kDa}$ and $c .83 \mathrm{kDa}$, respectively [26].

The steps used in the purification of biologically active Men-E2 $p$ were similar to those used for the isolation of E2p from $A$. vinelandii [25]. The isolated Men-E2p did not contain E. coli E3, indicating that the E3 component of $E$. coli PDHC did not interact with Men-E2p. This made the purification procedure for Men-E2p much simpler than that for $A$. vinelandii E2p. The purified Men-E2p had a specific E2p activity of $58 \mathrm{U} / \mathrm{mg}$ (Table 1), which is similar to that of 


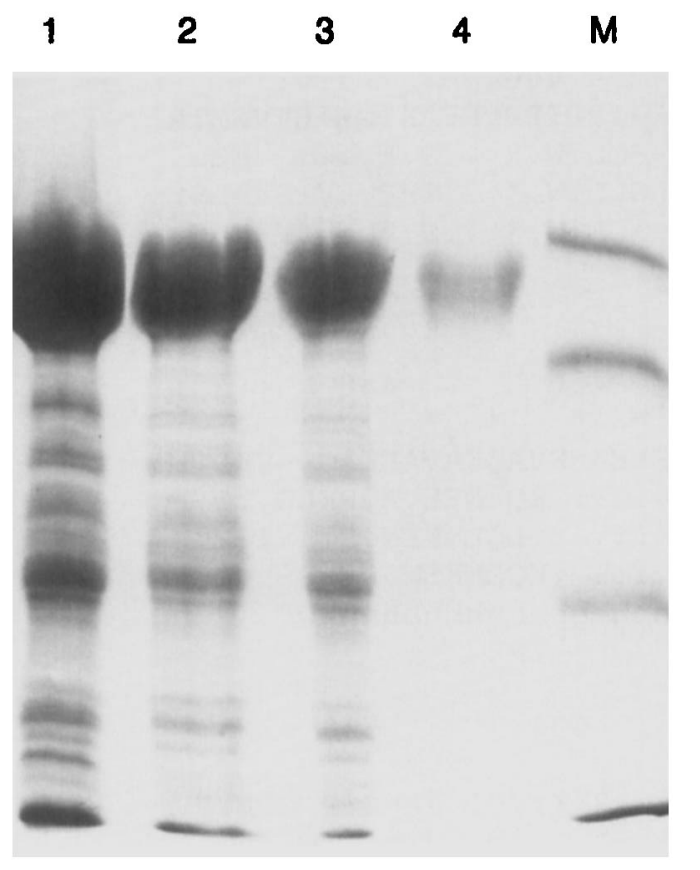

$\mathrm{kDa}$

Fig. 5. Purification of meningococcal E2p expressed in $E$. coli TG2 (pSK34a). Samples from different stages of the isolation procedure were subjected to SDS-PAGE. Lane M, low mol.wt markers (Sigma) (kDa); 1, cell-free extract; 2, supernate after protamine sulphate precipitation; 3, concentrated supernate after protamine sulphate precipitation; 4, pooled from Sephacryl S-400HR.

purified $A$. vinelandii E2p (54-79 $\mathrm{U} / \mathrm{mg}$ ) [25]. The sequence of the first $10 \mathrm{~N}$-terminal amino acids of the purified Men-E2p was determined, and shown to be (M)SIVEIKVPDI, confirming the predicted sequence of the mature protein. The initiating methionine was only partially removed.

\section{Immunochemical characterisation of Men-E2p}

Rabbit antiserum was raised against the purified MenE2p (extracted from preparative SDS-polyacrylamide gels) and compared in immunoblots with the R-70 antiserum. Both antisera reacted strongly with the purified Men-E2p (Fig. 6, lanes 3 and 5).

The predicted amino-acid sequence of Men-E2p shows the presence of several lysine residues in all linker regions and, therefore, it was predicted that limited proteolysis with trypsin would yield a single lipoyl domain $(c .16 \mathrm{kDa})$, a catalytic domain $(c .30 \mathrm{kDa})$, a lipoyl-lipoyl di-domain (c. $36 \mathrm{kDa})$ and a lipoyl-E1/E3 binding-catalytic tri-domain (c. $54 \mathrm{kDa}$ ). SDS-PAGE analysis (Fig. 6) showed that all the predicted fragments were present (lane 2), with the lipoyl-E1/ E3 binding-catalytic tri-domain, the lipoyl-lipoyl didomain and the catalytic domain being the main fragments, and the single lipoyl domain being a minor product. These fragments are also present in the undigested E2p (lane 1) albeit in minor amounts. They probably originate from proteolytic activity in the TG2 cells. Rabbit anti-Men-E2p serum (Fig. 6, lanes 5 and 6) reacted strongly with all the fragments (i.e., all the domains), whereas R-70 antiserum (lanes 3 and 4) showed a stronger reaction against fragments which contained the lipoyl domain and a much weaker reaction against the catalytic domain.

Purified Men-E2p also reacted with antisera previously raised against the native dihydrolipoyl acetyltransfer-

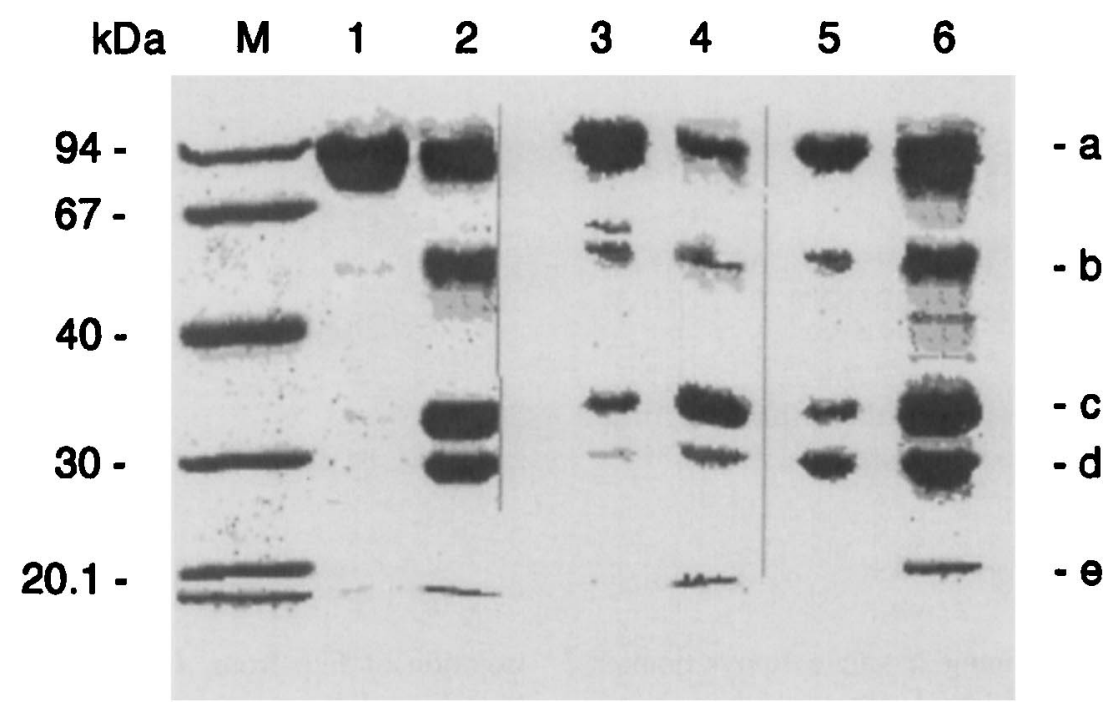

Fig. 6. Coomassie Brilliant Blue-stained SDS-polyacrylamide gel (lanes M, 1 and 2) and immunoblots (lanes 3-6) of purified meningococcal E2p treated with trypsin. Lane $\mathbf{M}$, low mol. wt markers (kDa); 1, 3, 5, purified E2p; 2, 4, 6, E2p digested with trypsin; 3 and 4, blot incubated with R-70 antiserum; 5 and 6, blot incubated with anti Men-E2p antiserum. Fragments visible: a, intact E2p; b, lipoyl-E1/E3 binding-catalytic tri-domain; c, lipoyl-lipoyl di-domain; d, catalytic domain; e, single lipoyl domain. Equal amounts of E2p were added to each lane. 
ase of $A$. vinelandii (Fig. 1, lane d) and that raised to its lipoyl domain (Fig. 1, lane e). This further indicated that E2p is highly conserved across species in terms of immunoreactivity. Also, rabbit anti-MenE2p antiserum cross-reacted with total proteins of $A$. vinelandii, E. coli and N. gonorrhoeae (not shown). Men-E2p failed to react with a murine monoclonal anti-FrpB antibody, MAb-M70 (not shown), indicating that this protein is different from the $c .70-\mathrm{kDa}$ ironregulated FrpB. This was further confirmed when rabbit anti-Men-E2p serum reacted equally well with the OMVs obtained from meningococci (strain SD) grown under iron-sufficient (Fig. 1, lane c) and ironrestricted conditions (not shown).

It was of interest to determine whether or not MenE2p is immunogenic following meningococcal infection. Rabbit antisera, raised against live meningococcal strains SD (B:15:P1.16) (the strain used for MenE2p cloning), AS (A:4:P1.7) and EB (29E), and the commensal strain, $N$. lactamica, reacted strongly with purified Men-E2p in immunoblots (Fig. 7, lanes a-d). Murine antisera raised against live meningococcal strains SD and B16B6 (B:2a:P1.2) also reacted with Men-E2p (Fig. 7, lanes $e$ and $f$ ). No reaction was detected when rabbit or murine pre-immune sera were used (not shown).

Antibodies to purified Men-E2p were also detected in human convalescent sera obtained from three patients who had recovered from meningococcal diseases caused by three different strains, including strain SD, JB (C:NT) and GLD (C:2a:P1.10), and one patient who recovered from gonococcal pelvic inflamatory disease (Fig. 6, lanes $\mathrm{g}-\mathrm{j}$ ). It is important to note that normal human serum, obtained from a healthy individual with no history of meningococcal or gonococcal infection, also showed a very weak reaction with Men-E2p (not shown because the band was lost on photoreproduction).

\section{Discussion}

The pyruvate dehydrogenase complex of many gramnegative bacteria contains three enzymic components, pyruvate dehydrogenase (E1p), dihydrolipoyl acetyltransferase (E2p) and dihydrolipoyl dehydrogenase (E3). These are encoded by three genes (aceE, aceF and $l p d$ ) [27]. Thus far, three dihydrolipoyl acetyltransferases from gram-negative organisms have been sequenced and characterised [20-22]. The E2p from $N$. meningitidis (Men-E2p) characterised in this study presents the fourth example. Men-E2p has a domain structure that compares very well with that of other E2ps. From the sequence analysis it was clear that it contains two N-terminal lipoyl domains, an E1/E3 binding domain and a catalytic domain. The domains are separated by hinge regions rich in alanine, proline and charged residues. Men-E2p shares a high degree of homology with the E2p of the other three bacteria, with $50-55 \%$ sequence identity in each of the domains. Unlike $E$. coli and $A$. vinelandii enzymes, Men-E2p lacks a third lipoyl domain. Instead, and similar to the PDHC of Al. eutrophus [22], meningococci seem to express an additional lipoyl domain on the N-terminus of the E3 component. The function of this lipoyl domain in the overall catalysis by the complex remains an interesting aspect for future research. Another interesting feature is the presence of an additional reading frame, ORF3, between the coding regions of $E 2 p$ and E3. Expression of a protein that corresponds to ORF3 (16.5 kDa) has not been observed. A similar ORF has been identified only in Al. eutrophus. However, unlike the latter, the codon usage of the meningococcal ORF3 is very different from the other

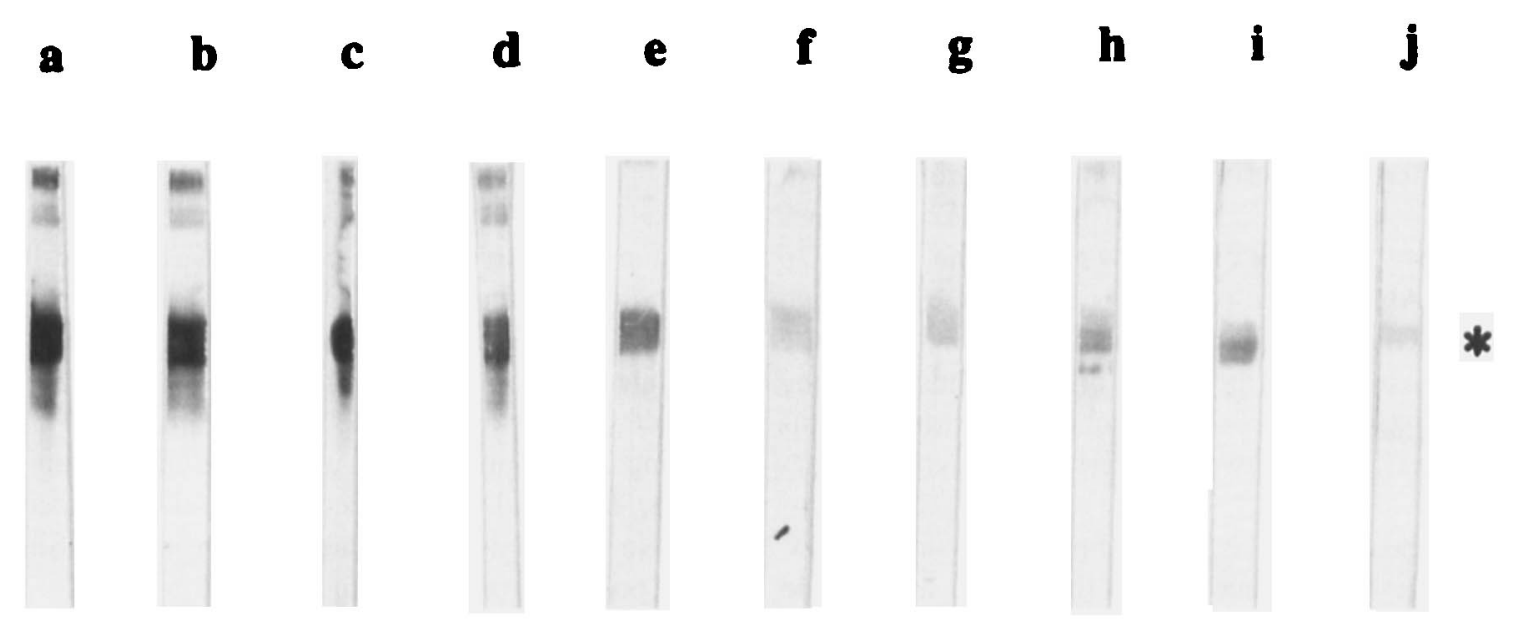

Fig. 7. Immunoblots of purified Men-E2p probed with antisera to live strains: a-d, probed with rabbit antiserum to live $N$. meningitidis strains $\mathrm{SD}, \mathrm{AS}, \mathrm{EB}$ and live $N$. lactamica, respectively; $\mathbf{e}-\mathbf{f}$, probed with murine antiserum to strains SD and Bl6B6; $\mathbf{g}-\mathbf{j}$, probed with human convalescent sera from patients infected with $N$. meningitidis strains SD, JB, GLD and $N$. gonorrhoeae, respectively. ${ }^{*}$ c. $70 \mathrm{kDa}$. 
coding regions so it is doubtful that it codes for an additional protein.

The sequence of four highly similar E2p proteins from gram-negative organisms, together with the availability of structures of each of the domains [28-30], allows a detailed structure-based comparison (Fig. 4). The sequence around the lipoyl-lysine residues, Lys ${ }^{39}$ and Lys $^{156}$ ( $A$. vinelandii numbering throughout), is strongly conserved. These residues are located in a type I turn connecting beta strands $\mathrm{Ad}$ and Ae. The extent of lipoylation has not been analysed. Strong conservation is also observed in the E1/E3 binding domain, especially around helix $\mathrm{BH} 1$. This helix is thought to be involved in E3 binding [31]. Despite strong sequence conservation, the affinity of $E$. coli E3 for Men-E2p must be weak as this enzyme was not associated with Men-E2p during purification. In contrast, it was found that $\mathrm{E} 3$ from $A$. vinelandii bound strongly to Men-E2p (not shown) and weakly to E. coli $\mathrm{E} 2 \mathrm{p}$ [32]. The reason for these differences in affinity is not obvious from a sequence comparison of the binding domain alone. In the catalytic domain, the important catalytic site residues $\mathrm{Ser}^{558}$ and $\mathrm{His}^{610}$ are, as predicted, conserved. A. vinelandii $\mathrm{E} 2 \mathrm{p}$ is the only known E2p that has an $\mathrm{Asn}^{614}$, this being an Asp in the other sequences. On the basis of mutagenesis experiments, it has been suggested recently that charge neutralisation of $\mathrm{Asp}^{614}$ is required for an optimal catalytic function of the nearby $\mathrm{His}^{610}$ [33]. Modelling experiments indicated that in $E$. coli $\mathrm{E} 2 \mathrm{p}$ charge neutralisation might result from salt bridge formation between $\mathrm{Arg}^{483}$ and $\mathrm{Asp}^{614}$. In the sequences from $\mathrm{Al}$. eutrophus and $N$. meningitidis, $\operatorname{Arg}^{483}$ is replaced by Asp and Glu, respectively, which indicates that the formation of a salt bridge, as in $E$. coli, is unlikely.

Another interesting observation from the sequence comparison concerns the stability of the E2p core. In $A$. vinelandii, this core dissociates into trimers upon binding of the peripheral components, while the other $E 2 p$ cores remain cubic. The intertrimer interaction is of hydrophobic character and the interface is formed by the C-terminal helix $\mathrm{CH} 6$, the $\mathrm{N}$-terminal part of helix $\mathrm{CH} 4$ and one face of helix $\mathrm{CH} 2$ (residues indicated by asterisk in Fig. 4). In the Men-E2p sequence $\mathrm{Ala}^{634}$ of helix $\mathrm{CH} 6$ is replaced by Arg and $\mathrm{Val}^{456}$ by Glu. Modelling experiments show that these residues can form a salt bridge, thus causing additional stabilisation of the cubic core. Mutagenesis experiments are underway to verify this hypothesis.

The predicted sequence of the lipoyl domain from $N$. meningitidis E3 (deduced from the ORF4 amino-acid sequence) is almost identical to that of the $\mathrm{N}$-terminal lipoyl domain of Men-E2p. We have recently shown that R-70 and rabbit anti Men-E2p antisera cross-react with meningococcal E3 (unpublished observations). E3 seems most likely to be the same protein as the meningococcal OMP64 characterised by Silva et al.
[23], which migrates as a $c$. $70-\mathrm{kDa}$ protein in SDSpolyacrylamide gels. Therefore, it is likely that this protein co-migrates, and hence co-purifies, with FrpB and Men-E2p. The observation that R-70 antibodies react more strongly with the lipoyl domain than with other epitopes from Men-E2p, adds to the possibility that the R-70 antibodies might react primarily with the E3 component and Men-E2p through cross-reactivity of the N-terminal lipoyl domain.

Silva et al. [23] suggested that OMP64 is an immunogenic OMP, likely to be surface exposed and, therefore, suitable for vaccine preparation. It is difficult to see a physiological role for E3 or the complex in the outer membrane. E3 might be expressed in excess to the amount required for binding to the multi-enzyme complex, for example, under regulation by ORF3. Free or complex-bound dihydrolipoyl dehydrogenase has been described as associated with the plasma membrane in some organisms [34-36], but unless an outer membrane localisation is verified, for example, by immunogold labelling of whole cells or cell sections, a contamination of the OMV preparation by other cell components cannot be excluded. The expression of meningococcal $\mathrm{E} 3$ in $E$. coli and its purification is being undertaken for further analysis of this question.

E2p is highly conserved across prokaryotic and eukaryotic species and it is interesting to note that Men-E2 $p$ is immunogenic in animals when used as purified protein or as a component of live organisms. More interestingly, patients who recovered from natural meningococcal or gonococcal disease also responded to Men-E2p, with cross-reactive antibodies. It is not known whether these antibodies are against conserved parts of Men-E2p which might be shared with man. If so, this will pose the risk of breaking immune tolerance and causing autoimmune disease. Indeed, patients with primary biliary cirrhosis produce antibodies directed against the lipoyl-lysine region of the lipoyl domains of all mammalian acyltransferases [37].

Silva et al. [23] found that antisera from vaccinees immunised with a Cuban vaccine (Va-mengoc-BC) [3] contained antibodies to OMP64 (i.e., probably E3). This indirect evidence indicates that the vaccine contains E3 protein. The presence of Men-E2p in this vaccine is also possible, considering that, at least during OMV preparation under non-denaturing conditions, E2p and E3 molecules would be expected to remain interactive and, therefore, co-purify. Similarly, the possible presence of Men-E2p or E3 in the Norwegian OMV-based vaccine preparation cannot be excluded, as it is known that this vaccine, like the Cuban preparation, contained the iron-regulated FrpB $[38,39]$. It is not known whether patients with a history of neisserial infection, or vaccinees, are more likely to develop autoimmune disease than the normal 
population. However, normal individuals are exposed to common respiratory neisseriae. This may explain why the normal human serum examined contained antibodies against Men-E2p, although they were of either low quantity or affinity. Clearly, much better understanding of the immunochemistry of, and the human immune response to, meningococcal OMV components is required before a safe and effective vaccine can be developed.

This study was supported by an MRC programme grant no. G9122850 (UK), the Netherlands Foundation for Chemical Research (SON) and the Netherlands Organisation for Scientific Research (NWO). We thank Dr R. Amons (Leiden University, Netherlands) for the N-terminal sequence analysis and Drs $\mathrm{H}$. Palmer and P. Hill (Nottingham University) for useful discussions.

\section{References}

1. Ala'Aldeen DAA, Griffiths E. Vaccines against meningococcal diseases. In: Ala'Aldeen DAA, Hormaeche CE (eds) Molecular and clinical aspects of bacterial vaccine development. Chichester, John Wiley and Sons Ltd. 1995: 1-39.

2. Bjune G, Høiby EA, Grønnesby JK et al. Effect of outer membrane vesicle vaccine against group $B$ meningococcal disease in Norway. Lancet 1991; 338: 1093-1096.

3. Sierra GVG, Campa HC, Varcacel NM et at. Vaccine against group B Neisseria meningitidis: protection trial and mass vaccination results in Cuba. NIPH Ann 1991; 14: 195-210.

4. De Moraes JC, Perkins BA, Camargo MCC et al. Protective efficacy of a serogroup B meningococcal vaccine in Sao Paulo, Brazil. Lancet 1992; 340: 1074-1078.

5. Ala'Aldeen DA, Wall RA, Borriello SP. Immunogenicity and cross-reactivity of the $70-\mathrm{kDa}$ iron-regulated protein of Neisseria meningitidis in man and animals. $J$ Med Microbiol 1990; 32: 275-281.

6. Ala'Aldeen DAA, Davies HA, Borriello SP. Vaccine potential of meningococcal FrpB: studies on surface exposure and functional attributes of common epitopes. Vaccine 1994; 12: $535-541$

7. Pettersson A, Kuipers B, Pelzer $\mathrm{M}$ et al. Monoclonal antibodies against the $70 \mathrm{kDa}$ iron-regulated protein of Neisseria meningitidis are bactericidal and strain specific. Infect Immun 1990; 58: 3036-3041.

8. Pettersson AM, Maas A, van Wassenaar D, van der Ley $P$, Tommassen J. Molecular characterization of FrpB, the 70kilodalton iron-regulated outer membrane protein of Neisseria meningitidis. Infect Immun 1995; 63: 4181-4184.

9. Aoun L, Cremieux AC, Casin I, Morel P, Martin PM. Serum antibody response to the 70,000 -molecular-weight neisserial common antigen in humans infected by Neisseria gonorrhoeae. I Clin Microbiol 1988; 26: $1898-1900$.

10. Ala'Aldeen DA, Davies HA, Wall RA, Borriello SP. The 70 kilodalton iron regulated protein of Neisseria meningitidis is not the human transferrin receptor. FEMS Microbiol Lett 1990; 69: $37-42$.

11. Gibson TJ. Studies on the Epstein-Barr virus genome. $\mathrm{PhD}$ Thesis, University of Cambridge, 1984.

12. Palmer HM, Powell NBL, Ala'Aldeen DA, Wilton J, Borriello SP. Neisseria meningitidis transferrin-binding protein $1 \mathrm{ex}-$ pressed in Escherichia coli is surface exposed and binds human transferrin. FEMS Microbiol Lett 1993; 110: 139-146.

13. Griffiths E, Stevenson P, Ray A. Antigenic and molecular heterogeneity of the transferrin-binding protein of Neisseria meningitidis. FEMS Microbiol Lett 1990; 69: 31-36.

14. Ala'Aldeen DA, Stevenson P, Griffiths $\mathrm{E}$ et al. Immune responses in human and animals to meningococcal transferrinbinding proteins: implications for vaccine design. Infect Immun 1994; 62: 2984-2900

15. Ausubel FM. Current protocols in molecular biology. New York, John Wiley and Sons, 1987.

16. Schwartz ER, Reed LJ. Alpha-keto acid dehydrogenase complexes. XII. Effects of acetylation on the activity and structure of the dihydrolipoyl transacetylase of Escherichia coli. J Biol Chem 1969; 244: 6074-6079.

17. Reed LJ, Koike M, Levitch ME, Leach FR. Studies on the nature and reactions of protein-bound lipoic acid. $J$ Biol Chem 1958; 232: $143-158$.

18. Goa J. A micro-biuret method for protein determination of total protein in cerebrospinal fluid. Scand J Clin Lab Invest 1953; 5: $218-222$

19. Bensadoun A, Weinstein D. Assays of proteins in the presence of interfering materials. Anal Biochem 1976; 70: 241-250.

20. Stephens PE, Darlison MG, Lewis HM, Guest JR. The pyruvate dehydrogenase complex of Escherichia coli K12. Nucleotide sequence encoding the dihydrolipoamide acetyltransferase component. Eur J Biochem 1983; 133: 481-489.

21. Hanemaaijer R, Janssen A, de Kok A, Veeger C. The dihydrolipoyltransacetylase component of the pyruvate dehydrogenase complex from Azotobacter vinelandii. Molecular cloning and sequence analysis. Eur $J$ Biochem 1988; 174: 593-599.

22. Hein S, Steinbüchel A. Biochemical and molecular characterization of the Alcaligenes eutrophus pyruvate dehydrogenase complex and identification of a new type of dihydrolipoamide dehydrogenase. J Bacteriol 1994; 176: 4394-4408.

23. Silva R, Selman $M$, Guillen $G$ et al. Nucleotide sequence coding for an outer membrane protein from Neisseria meningitidis and use of said protein in vaccine preparations. European Patent Application 1991; 0474313 A2.

24. Beucher M, Sparling PF. Cloning, sequencing, and characterization of the gene encoding FrpB, a major iron-regulated, outer membrane protein of Neisseria gonorrhoeae. $J$ Bacteriol 1995; 177: 2041-2049.

25. Hanemaaijer R, Westphal AH, Berg A, van Dongen W, de Kok $A$, Veeger $C$. The gene encoding dihydrolipoyl transacetylase from Azotobacter vinelandii. Expression in Escherichia coli and activation and isolation of the protein. Eur $J$ Biochem 1989; 181: 47-53

26. Schulze E, Westphal AH, Veenhuis M, de Kok A. Purification and cellular localization of wild-type and mutated dihydrolipoyltransacetylases from Azotobacter vinelandii and Escherichia coli expressed in E. coli. Biochim Biophys Acta 1992; 1120: $87-96$.

27. Guest JR, Angier SJ, Russell GC. Structure, expression, and protein engineering of the pyruvate dehydrogenase complex of Escherichia coli. Ann N Y Acad Sci 1989; 573: 76-99.

28. Mattevi A, Obmolova G, Schulze E et al. Atomic structure of the cubic core of the pyruvate dehydrogenase multienzyme complex. Science 1992; 255: 1544-1550.

29. Robien MA, Clore M, Omichinski JG et al. Three-dimensional solution structure of the E3-binding domain of the dihydrolipoamide succinyltransferase core from the 2-oxoglutarate dehydrogenase multienzyme complex of Escherichia coli. Biochemistry 1992; 31: 3463-3471.

30. Berg A, de Kok A, Vervoort J. Sequential $1 \mathrm{H}$ and $15 \mathrm{~N}$ nuclear magnetic resonance assignments and secondary structure of the $\mathrm{N}$-terminal lipoyl domain of the dihydrolipoyl transacetylase component of the pyruvate dehydrogenase complex from Azotobacter vinelandii. Eur J Biochem 1994; 221: 87-100.

31. Westfal AH, Fabisz-Koyvska A, Kester H, Obels PP, de Kok A The interaction between lipoamide dehydrogenase and the peripheral-component-binding domain from the Azotobacter vinelandii pyruvate dehydrogenase complex. Eur $J$ Biochem 1996; 234: 861-870.

32. de Kok A, Westphal AH. Hybrid pyruvate dehydrogenase complexes reconstituted from components of the complexes from Escherichia coli and Azotobacter vinelandii. Eur $J$ Biochem 1985; 152: 35-41.

33. Hendle J, Mattevi A, Westphal $\mathrm{AH}$ et al. Crystallographic and enzymatic investigations on the role of Ser558, His610, and Asn614 in the catalytic mechanism of Azotobacter vinelandii dihydrolipoamide acetyltransferase (E2p). Biochemistry 1995; 34: 4287-4298.

34. Richarme G. Purification of a new dihydrolipoamide dehydrogenase from Escherichia coli. J Bacteriol 1989; 171: 65806585 .

35. Hamilä H, Palva A, Paulin L, Arvidson S, Palva I. Secretory S complex of Bacillus subtilus: sequence analysis and identity to pyruvate dehydrogenase. $J$ Bacteriol 1990; 172: 5052-5063.

36. Else AJ, Hough DW, Danson MJ. Cloning, sequencing, and expression of Trypanosoma brucei dihydrolipoamide 
dehydrogenase. Eur J Biochem 1993; 212: 423-429.

37. Fussey SPM, Guest JR, James OFW, Bassendine MF, Yeaman SJ. Identification and analysis of the major M2 autoantigens in primary biliary cirrhosis. Proc Natl Acad Sci USA 1988; 85: 8654-8658.

38. Fredriksen JH, Griffiths E, Grotterød EM et al. Characterization of high molecular weight components in Men B - vaccine "Folkhelsa": an outer membrane vesicle vaccine against group
B meningococcal disease. In: Conde-Glez CJ, Morse S, Rice P, F.S, Calderon E (eds) Pathobiology and immunobiology of Neisseriaceae. Cuernavaca, Mexico: Publications office of the Instituto Nacional de Salud Publica, 1994: 818-824.

39. Griffiths E, Sierra G, Holst J. Quality control of the Cuban and Norwegian serogroup B vaccines used in the Iceland study. In: Evans JS, Susan EY, Martin CJM, Feavers IM (eds) Neisseria 1994. Potters Bar, UK, NIBSC. 1994: 437. 